\title{
Effects of Various Curing Conditions on Volume Stability of Magnesium Phosphate Cement
}

\author{
Jie Wu $\left(\mathbb{D}\right.$, Zhenyu Lai $\mathbb{D}^{\text {, }}$, Qiubai Deng $(\mathbb{D}$, and Mengliang Liu $\mathbb{1}$ \\ Southwest University of Science and Technology, School of Materials Science and Engineering, \\ State Key Laboratory of Environmental-Friendly Energy Materials, Mianyang, Sichuan 621010, China
}

Correspondence should be addressed to Zhenyu Lai; laizhenyu@swust.edu.cn

Received 8 October 2020; Revised 10 January 2021; Accepted 16 January 2021; Published 30 January 2021

Academic Editor: Hongchao Kou

Copyright $(2021$ Jie Wu et al. This is an open access article distributed under the Creative Commons Attribution License, which permits unrestricted use, distribution, and reproduction in any medium, provided the original work is properly cited.

Magnesium phosphate cement (MPC) is an excellent repair material for civil and road engineering, but its volume stability under various environmental conditions significantly influences these applications. In this study, the volume stability of MPC under different curing conditions (e.g., air, standard, and water curing) is investigated. Moreover, the phases, weight loss, microstructure, and pore structure of the samples have been determined by X-ray diffraction, thermogravimetry, scanning electron microscopy, and Brunnauer-Emmet-Teller method. The results show that MPC will shrink by $8 \times 10^{-4}$ under air-curing conditions. At the same time, MPC will expand by $9 \times 10^{-4}$ under water-curing and standard curing conditions, which means that curing conditions influence the volume stability of MPC. Not only that, compared with air-curing conditions, the compressive strength of MPC under standard curing and water-curing conditions will decrease by $30 \%$ and $60 \%$, respectively, which implies that greater humidity will reduce the mechanical properties of the repair material. Therefore, air curing is the best curing condition for MPC. To get a better repair effect, the environment should be avoided as much as possible in a humid state. The microscopic analysis results show that the volume expansion of MPC is related to hydration products, and the volume shrinkage occurs owing to drying shrinkage caused by internal moisture evaporation.

\section{Introduction}

Nowadays, concrete is widely used in civil and road engineering. Due to heavy traffic loads and various environmental conditions, the concrete structure is damaged by increasing service life $[1,2]$. It is very important to use repair materials to restore concrete structures' performance [3,4]. At present, due to its fast setting time, high early strength, and bond strength with the old concrete, magnesium phosphate cement (MPC) is often used for the fast repairing of the concrete structure [5].

MPC is a new and excellent type of repair material, with the characteristics of early high strength [6], good bonding performance [7], wear resistance [8], freeze-thaw cycle stability [9], and good resistance to acid attacks [10, 11]. MPC is a cementitious material formed through a chemical reaction between dead-burned $\mathrm{MgO}$ and phosphate (KDP) $[12,13]$. In the early MPC period as a repair material in civil engineering applications, ammonium dihydrogen phosphate (APD) was typically used as the phosphate. The hydration product is mainly hexahydrate magnesium ammonium phosphate (MAP), a naturally occurring crystal commonly known as struvite [14]. However, ammonia $\left(\mathrm{NH}_{3}\right)$ is a toxic gas obtained as a by-product of the hydration reaction. Not only will it endanger human health but it also pollutes the environment to a certain extent. Therefore, in recent studies, potassium dihydrogen phosphate (KDP) has usually been used as the phosphate $[7,9,15]$. The hydration reaction product between $\mathrm{MgO}$ and KDP is hexahydrate magnesium potassium phosphate $\left(\mathrm{KMgPO}_{4} \cdot 6 \mathrm{H}_{2} \mathrm{O}\right)[10,14,16,17]$. Because of $\mathrm{KMgPO}_{4} \cdot 6 \mathrm{H}_{2} \mathrm{O}$ having similar properties as struvite, it is often called $\mathrm{K}$-struvite. The formation of $\mathrm{K}$-struvite is depicted as follows $[6,18]$ :

$$
\mathrm{MgO}+\mathrm{KH}_{2} \mathrm{PO}_{4}+5 \mathrm{H}_{2} \mathrm{O}=\mathrm{KMgPO}_{4} \cdot 6 \mathrm{H}_{2} \mathrm{O} .
$$


For all types of concrete pavement structure repair, volume stability is an essential factor to be considered when evaluating the properties of repair materials. It relates to the success or failure of repairing damaged structures. Material shrinkage and expansion rate are two apparent quantitative indicators of volume stability. If the volume shrinkage of the repair material is very high, the hardening slurry will produce tensile stress, which will result in cracks between the repair material and the interface [19]. Conversely, if the volume expansion of the repair material is too large, expansion stress will be produced, which will reduce the strength [15]. Therefore, it is essential to study the volume stability of MPC for the repair of damaged concrete pavement structures in detail.

Besides, according to relevant literature studies of cement-based materials, different service environments will have different effects on the volume stability of cementitious materials [20]. The proper curing methods can effectively increase the strength and reduce the central temperature due to hydration heat and the early shrinkage strain [21]. The repair material's service in such an environment implies that the curing conditions may also have a certain impact on the volume stability and other properties of MPC. Recent research on MPC has mainly focused on mechanical properties [22-25], solidification [26-30], setting time [31, 32], microstructure [33-35], and hydration reaction mechanisms $[36,37]$. These studies lack the performance research on the volume stability of MPC in different environments. Therefore, studying the volume stability of MPC under various curing conditions is of great significance to the application and promotion of this material in the field of repair.

In this paper, the main objective is to analyze the influence of the volume stability and compressive strength of MPC under various curing conditions. The phase composition, microstructure, weight loss, and as-prepared samples' pore structure were investigated to discuss volume stability mechanisms.

\section{Experimental Details}

2.1. Raw Material. In this study, the raw materials included dead-burned MgO, KDP, and borax. Dead-burned MgO was obtained by calcining magnesite at $1650^{\circ} \mathrm{C}$ and was supplied by Yancheng Huanai Magnesium Industry Co. Ltd., China. The dead-burned $\mathrm{MgO}$ was an earthy yellow powder, and its chemical composition is shown in Table 1. The MgO particle size distribution was measured three times, and the results are shown in Figure 1. The average particle diameter of magnesium oxide is $18.7 \mu \mathrm{m}$, and the specific surface area is $779.5 \mathrm{~m}^{2} / \mathrm{kg}$. The three measurement data are close to each other, which indicates that the accuracy of the results of magnesium oxide particle size is guaranteed. KDP was supplied by Shengfeng Phosphorus Chemical Co. Ltd., Shifang, Sichuan, China. Borax was provided by Chengdu Kelong Chemical Reagent Co. Ltd., China. KDP and borax were of the industrial grade, and their net content was $99 \%$ and $99.5 \%$, respectively. The water used was laboratory tap water.
TABLE 1: Chemical composition of MgO.

\begin{tabular}{lccccccc}
\hline Oxide & $\mathrm{MgO}$ & $\mathrm{SiO}_{2}$ & $\mathrm{CaO}$ & $\mathrm{Fe}_{2} \mathrm{O}_{3}$ & $\mathrm{Al}_{2} \mathrm{O}_{3}$ & $\mathrm{P}_{2} \mathrm{O}_{5}$ & Else \\
\hline Content (wt. \%) & 84.46 & 8.08 & 5.07 & 0.97 & 0.64 & 0.62 & 0.16 \\
\hline
\end{tabular}

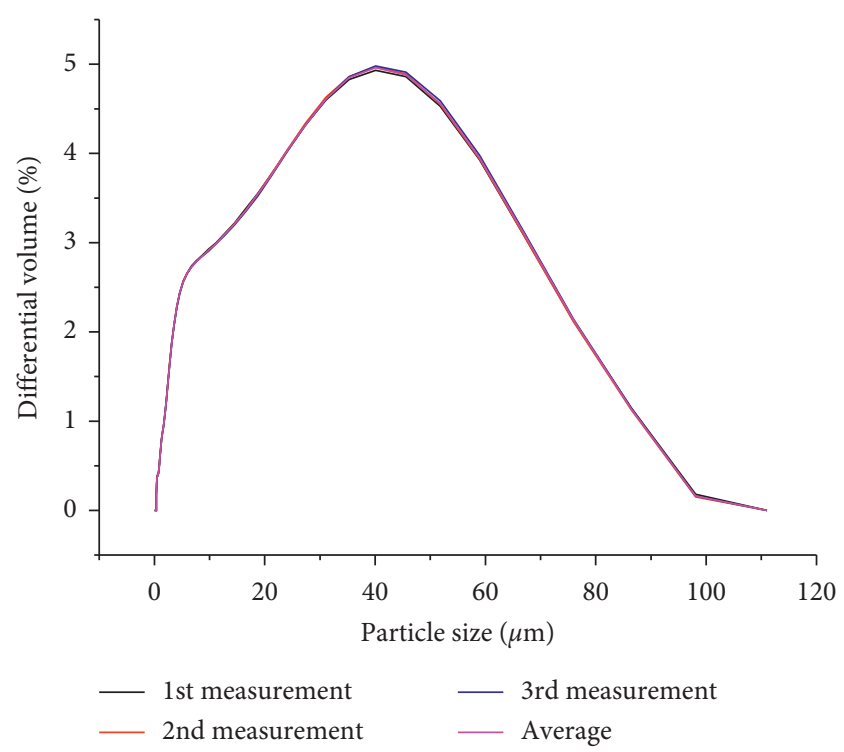

Figure 1: The particle size distribution of the dead-burned magnesia.

2.2. Mix Proportions and Curing Conditions. The mix proportions of MPC and curing conditions are listed in Table 2. The mass ratio of $M / P$ ranges from 3 to 5 . The borax content is $10 \%$ of the $\mathrm{MgO}$ mass. The water to $\mathrm{MgO}$ and $\mathrm{KDP}$ masses ratio is 0.14 .

The samples were cured under various curing conditions such as air, standard, and water curing. During air curing, the temperature of $20 \pm 2{ }^{\circ} \mathrm{C}$ and the relative humidity of $40 \pm 5 \%$ were maintained. During standard curing, the temperature of $20 \pm 2^{\circ} \mathrm{C}$ and the relative humidity of $95 \pm 5 \%$ were maintained. Water-curing conditions included complete immersion of the sample in water and keeping the water temperature at $20 \pm 2^{\circ} \mathrm{C}$.

2.3. Preparation of Samples. The samples were weighed according to the proportions of the raw materials in Table 2. First, they were mixed uniformly in a mixer, and then, water was added slowly for $10 \mathrm{~s}$. Following this, the mixtures were stirred slowly for $60 \mathrm{~s}$ and then quickly for $120 \mathrm{~s}$ to obtain MPC paste. The prepared MPC slurries were poured into a $25 \mathrm{~mm} \times 25 \mathrm{~mm} \times 280 \mathrm{~mm}$ tri-pass mold and into six $20 \mathrm{~mm} \times 20 \mathrm{~mm} \times 20 \mathrm{~mm}$ molds at one time, respectively. The mold with the samples was vibrated on the cement mortar vibrating table for $30 \mathrm{~s}$ and maintained for $3 \mathrm{~h}$ under the air-curing conditions. Finally, the mold was removed and cured for $1 \mathrm{~d}, 3 \mathrm{~d}, 7 \mathrm{~d}, 14 \mathrm{~d}, 21 \mathrm{~d}$, and $28 \mathrm{~d}$ under various curing conditions.

2.4. Test Methods. The volume stability of the MPC was determined according to the test method for determining the expansion ratio of expansive cement (JC/T 313-2009) [38]. 
TABLE 2: Mix proportions of MPC and curing conditions.

\begin{tabular}{lccc}
\hline$M / P^{\mathrm{a}}$ & $B / M^{\mathrm{b}}$ & $W / C^{\mathrm{c}}$ & Curing conditions \\
\hline $3: 1$ & 0.1 & 0.14 & Air \\
$3: 1$ & 0.1 & 0.14 & Standard \\
$3: 1$ & 0.1 & 0.14 & Water \\
$4: 1$ & 0.1 & 0.14 & Air \\
$4: 1$ & 0.1 & 0.14 & Standard \\
$4: 1$ & 0.1 & 0.14 & Water \\
$5: 1$ & 0.1 & 0.14 & Air \\
$5: 1$ & 0.1 & 0.14 & Standard \\
$5: 1$ & 0.1 & 0.14 & Water \\
\hline
\end{tabular}

$M / P^{\mathrm{a}}$ is the magnesia-to-potassium dihydrogen phosphate mass ratio. $B / M^{\mathrm{b}}$ is the borax-to-magnesia mass ratio. $W / C^{\mathrm{c}}$ is the water-to-magnesia and potassium dihydrogen phosphate mass ratio.

The samples' volume deformation under various curing conditions was measured with the BC-II digital length ratio instrument (Wuxi Jianyi, China). The samples' volume deformation is related to the relationship between the initial length and the length of the curing age. The MPC volume stability equation is written as follows:

$$
E_{X}=\frac{L_{x}-L_{1}}{250} \times 100 \text {. }
$$

Here, $E_{x}(\%)$ is the volume deformation of MPC at a certain age, the positive value means the expansion of the sample, and the negative value presents the sample's shrinkage. The length of the samples to be cured for a certain age is $L_{x}(\mathrm{~mm})$. The samples' time to be cured for $1 \mathrm{~h}$ under the air-curing conditions is $L_{1}(\mathrm{~mm})$. The effective length of the sample is $250(\mathrm{~mm})$. When the samples' three-volume deformation value differs by more than $0.010 \%$, the result is the average of the value with the smallest two absolute differences. In contrast, if the difference is less than $0.010 \%$, the result is their average.

The samples' compressive strength was investigated after curing for $1 \mathrm{~d}, 3 \mathrm{~d}, 7 \mathrm{~d}, 14 \mathrm{~d}, 21 \mathrm{~d}$, and $28 \mathrm{~d}$ using a TYE-300 instrument (Wuxi Jianyi, China) with a loading speed of $2.4 \mathrm{kN} / \mathrm{s}$. The compressive strength of the MPC was determined according to the method testing cement determination of strength (GB/T 17671-1999) [39]. If one of the six measured values exceeds $10 \%$ of the six averages, the result shall be eliminated, and the remaining five averages shall be used as the compressive strength result. If the five measured values exceed $10 \%$ of their average again, this group's results are invalidated.

The samples' phase compositions for $28 \mathrm{~d}$ were analyzed by the XRD (Dmax1400, Rigaku, Japan) using $\mathrm{Cu} \mathrm{K \alpha}$ radiation at $70 \mathrm{~mA}$ and $40 \mathrm{kV}$. The scanning step was 0.02 , and the scanning rate was $8^{\circ} / \mathrm{min}$ from $3^{\circ}$ to $80^{\circ}$. The samples' microstructure was investigated using a MAIA3 scanning electron microscope (TESCAN, Czech Republic). The thermal property of the MPC was analyzed by the TG (STA8000, Perkin Elmer, USA). The samples were heated from $30^{\circ} \mathrm{C}$ to $600^{\circ} \mathrm{C}$ in a nitrogen atmosphere at a heating rate of $20^{\circ} \mathrm{C} / \mathrm{min}$. The samples' pore structure was investigated using a specific surface area and porosity analyzer (Autosorb iQ, Quantachrome, USA). The gas adsorption type is nitrogen, and the samples were degassed at $40^{\circ} \mathrm{C}$ for $12 \mathrm{~h}$.

\section{Results and Discussion}

3.1. Effect of Curing Conditions on the Volume Stability of $M P C$. The volume stability of MPC is an essential factor to be considered when evaluating the properties. Figure 2 shows the volume of deformation rates of MPC with a different mass ratio under various curing conditions. Under the air-curing condition, the volume deformation of MPC shows expansion in the short term, and the volume deformation shows contraction in a long time. Besides, the shrinkage rate in the early stage is higher than that in the late stage. Moreover, under the standard curing and watercuring conditions, the volume deformation of MPC is shown as a slight expansion. Furthermore, under the same ratio of $M / P$, the volume expansion rate of magnesium phosphate cement under the water-curing condition is slightly higher than that of standard curing.

After $3 \mathrm{~d}$ of curing, it can be seen that MPC has a volume expansion under all curing conditions, and the volume expansion rates are about $4 \times 10^{-4}$. Moreover, under the same ratio of $M / P$, the volume expansion of the sample cured under water conditions is the largest, while that of the sample cured under air conditions is the smallest. The curing conditions' change resulted in different volume deformation characteristics, which showed that the curing conditions affect the volume stability.

The volume deformation of MPC after $42 \mathrm{~d}$ of curing under standard conditions for the $M / P$ ratios of $3: 1,4: 1$, and $5: 1$ was higher than the values obtained under the aircuring conditions by $8.56 \times 10^{-4}, 3.80 \times 10^{-4}$, and $4.02 \times 10^{-4}$, respectively. The volume expansion of MPC after $42 \mathrm{~d}$ of curing under water-curing conditions for the $M / P$ ratios of $3: 1,4: 1$, and $5: 1$ was higher than the values observed under the standard curing conditions by $0.50 \times 10^{-4}, 3.40 \times 10^{-4}$, and $1.20 \times 10^{-4}$, respectively. These results have shown that the volume expansion was the largest in water-curing conditions and the smallest in air-curing conditions. It is implied that MPC is sensitive to humidity and that the volume expansion increases with humidity.

MPC hydrates rapidly, and the hydration products will gradually change from phosphorrösslerite $\left(\mathrm{MgHPO}_{4} \cdot 7 \mathrm{H}_{2} \mathrm{O}\right)$ to newberyite $\left(\mathrm{MgHPO}_{4} \cdot 3 \mathrm{H}_{2} \mathrm{O}\right), \mathrm{Mg}_{2} \mathrm{KH}\left(\mathrm{PO}_{4}\right)_{2} \cdot 15 \mathrm{H}_{2} \mathrm{O}$, and $\mathrm{K}$-struvite during the hydration process [36]. Previous research shows that the amount of hydration products changes with the change in curing conditions. Similarly, different curing conditions may cause differences in the degree of hydration of MPC, resulting in differences in hydration products' types and quantities. Therefore, the variation in the volume deformation of MPC may be related to the type and the amount of hydration products under various curing conditions.

The volume deformation of MPC after $42 \mathrm{~d}$ of curing under air conditions for the $M / P$ ratios of $3: 1,4: 1$, and $5: 1$ was $-9.54 \times 10^{-4},-1.52 \times 10^{-4}$, and $-1.94 \times 10^{-4}$, respectively. The results showed that the volume of MPC shrunk under air-curing conditions. Drying shrinkage is the characteristic of cementitious materials, and it is caused by water diffusion and evaporation into the external environment. Moreover, under air-curing conditions, the sample's 


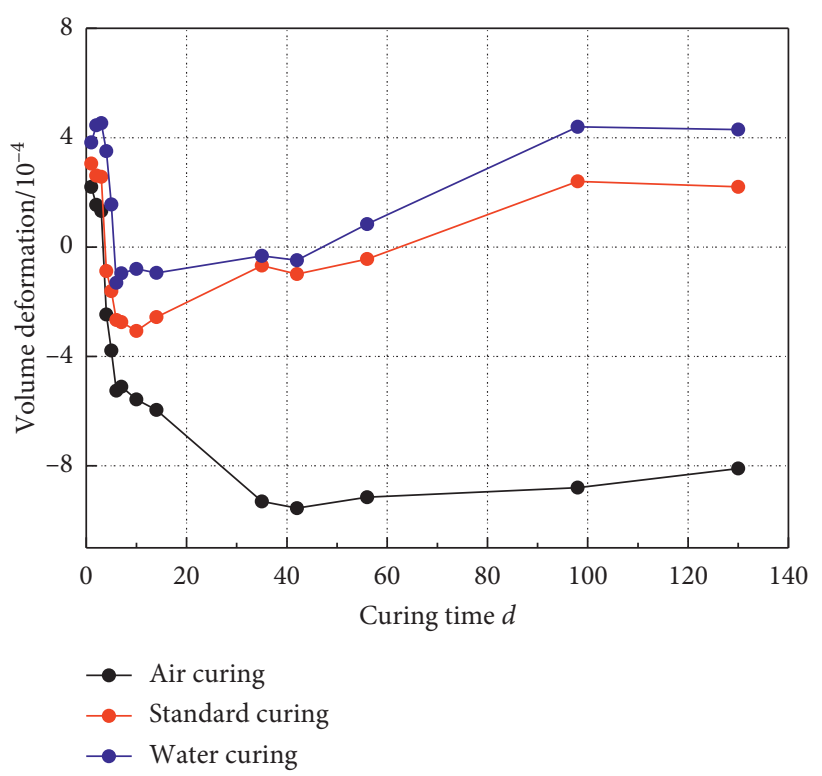

(a)

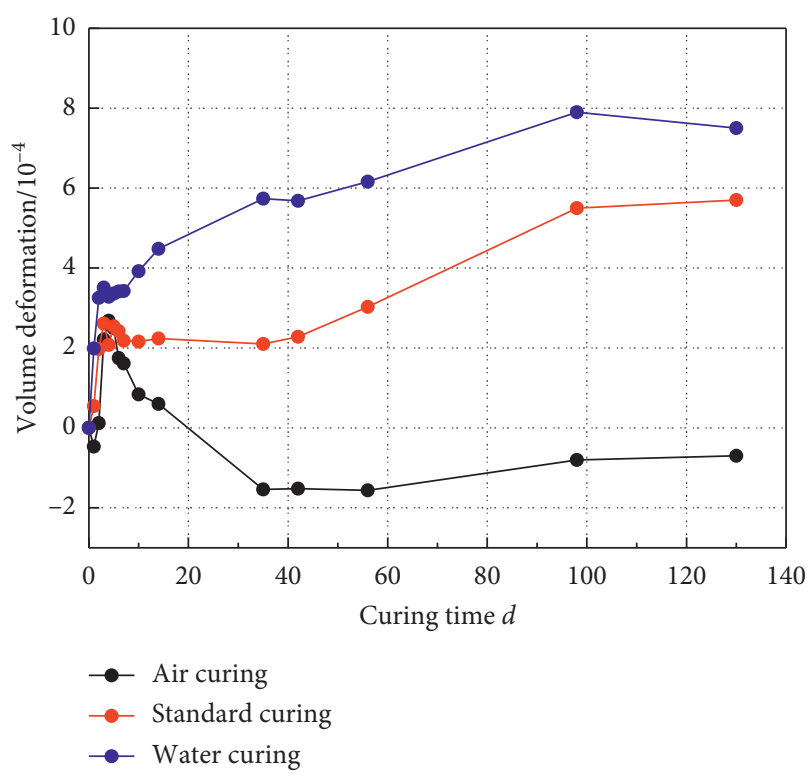

(b)

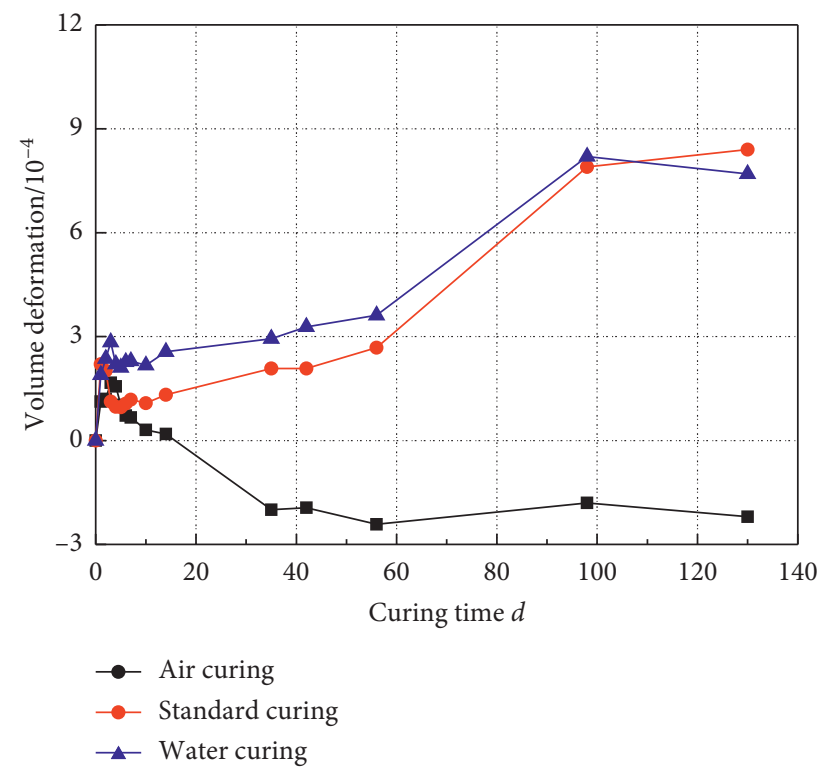

(c)

Figure 2: Volume deformation of MPC under various curing conditions. (a) $M / P=3: 1$, (b) $M / P=4: 1$, and (c) $M / P=5: 1$.

moisture continuously diffuses into the external environment, which causes volume shrinkage. This implied that the volume shrinkage deformation of MPC under air-curing conditions corresponds to drying shrinkage.

According to equation (1) for producing K-struvite, theoretically, the entire generation of 1 mole of K-struvite requires 1 mole of $\mathrm{MgO}, 1$ mole of $\mathrm{KH} 2 \mathrm{PO} 4$, and 5 moles of water. Therefore, under ideal conditions, the mass ratio of water to the cementitious material $(C=\mathrm{m} \quad(\mathrm{MgO})+\mathrm{m}$ $(\mathrm{KH} 2 \mathrm{PO} 4), W / C$ ) of the complete reaction of $\mathrm{MPC}$ is 0.511 , according to the following equation:

$$
\frac{W}{C}=\frac{m(\text { water })}{m(\mathrm{MgO})+m\left(\mathrm{KH}_{2} \mathrm{PO}_{4}\right)}=\frac{5 \times 18 \mathrm{~g} / \mathrm{mo}}{136.1 \mathrm{~g} / \mathrm{mo}+40.3 \mathrm{~g} / \mathrm{mo}}=0.510 .
$$

However, because dead-burned $\mathrm{MgO}$ has low reactivity, $\mathrm{MgO}$ cannot fully participate in the reaction. If this reaction equation's molar ratio is $1: 1: 5$, a large amount of KDP will remain in the MPC system because $\mathrm{MgO}$ did not wholly react. Moreover, because the amount of the cementitious material varies with the change in the $M / P$ ratio, the $W / C$ ratio is not a fixed value. Therefore, MPC cannot be fully 
hydrated at this molar ratio. However, the mass ratio of water to $\mathrm{KDP}(W / P)$ in the complete reaction of MPC was not affected by the $M / P$ ratio, which remained constant at 0.661, according to the following equation:

$$
\frac{W}{P}=\frac{m(\text { water })}{m\left(\mathrm{KH}_{2} \mathrm{PO}_{4}\right)}=\frac{5 \times 18 \mathrm{~g} / \mathrm{mo}}{136.1 \mathrm{~g} / \mathrm{mo}}=0.661 \text {. }
$$

The hydrolysis of KDP in water is expressed as follows:

$$
\begin{aligned}
& \mathrm{KH}_{2} \mathrm{PO}_{4}=\mathrm{K}^{+}+\mathrm{H}^{+}+\mathrm{HPO}_{4}{ }^{2-}, \\
& \mathrm{HPO}_{4}{ }^{2-}=\mathrm{H}^{+}+\mathrm{PO}_{4}{ }^{2-} .
\end{aligned}
$$

Therefore, $W / P$ better reflects whether the water consumption of MPC is sufficient or not. When the MPC has fully reacted ( $W / P=0.661)$, according to equations (6)-(9), the relationship between the $M / P$ ratio and the theoretical $W / C$ ratio in MPC can be established, which is shown in Figure 3. From the equation (9), it can be seen that the theoretical $W / C$ ratio is inversely proportional to the $M / P$ ratio. Figure 3 shows that the theoretical $W / C$ ratio gradually decreases as the $M / P$ ratio increases. When the ratio of $M / P$ is $3: 1,4: 1$, and $5: 1$, the theoretical $W / C$ ratio is $0.165,0.132$, and 0.110 , respectively.

$$
\begin{aligned}
\frac{W}{C} & =\frac{m(\text { water })}{m(\mathrm{MgO})+m\left(\mathrm{KH}_{2} \mathrm{PO}_{4}\right)}, \\
m(\text { water }) & =\frac{W}{P} \times m\left(\mathrm{KH}_{2} \mathrm{PO}_{4}\right)=0.661 \times m\left(\mathrm{KH}_{2} \mathrm{PO}_{4}\right), \\
m(\mathrm{MgO}) & =\frac{M}{P} \times m\left(\mathrm{KH}_{2} \mathrm{PO}_{4}\right), \\
\frac{W}{C} & =\frac{0.661 \times m\left(\mathrm{KH}_{2} \mathrm{PO}_{4}\right)}{(M / P) \times m\left(\mathrm{KH}_{2} \mathrm{PO}_{4}\right)+m\left(\mathrm{KH}_{2} \mathrm{PO}_{4}\right)} \\
& =\frac{0.661}{(M / P)+1} .
\end{aligned}
$$

In this experiment, the actual $W / C$ ratio is 0.14 . Under air-curing conditions, the actual $W / C$ ratio is $17.8 \%$ lower than the theoretical $W / C$ ratio when the ratio of $M / P$ is $3: 1$. This observation indicates that MPC is not fully hydrated. The actual $W / C$ ratios are $5.7 \%$ and $21.4 \%$ greater than the theoretical $W / C$ ratios when the $M / P$ ratios are $4: 1$ and $5: 1$, respectively. This means that the hydration reaction of MPC is complete under this condition. When the $M / P$ ratio is 3 , under air-curing conditions, the difference between theoretical and actual $W / C$ ratios increases due to water evaporation, making hydration less complete. Under standard and water-curing conditions, the hydration reaction of MPC is complete because there is no evaporation of water. It can be inferred that the amount of hydration products in the samples under air-curing conditions is lower than that under standard and water-curing conditions. There are more hydration products under standard and water-curing conditions, and the volume appears to be an expansion phenomenon. Under air-curing conditions, there are fewer hydration products. Hence, it can be speculated that hydration products may cause the expansion of magnesium

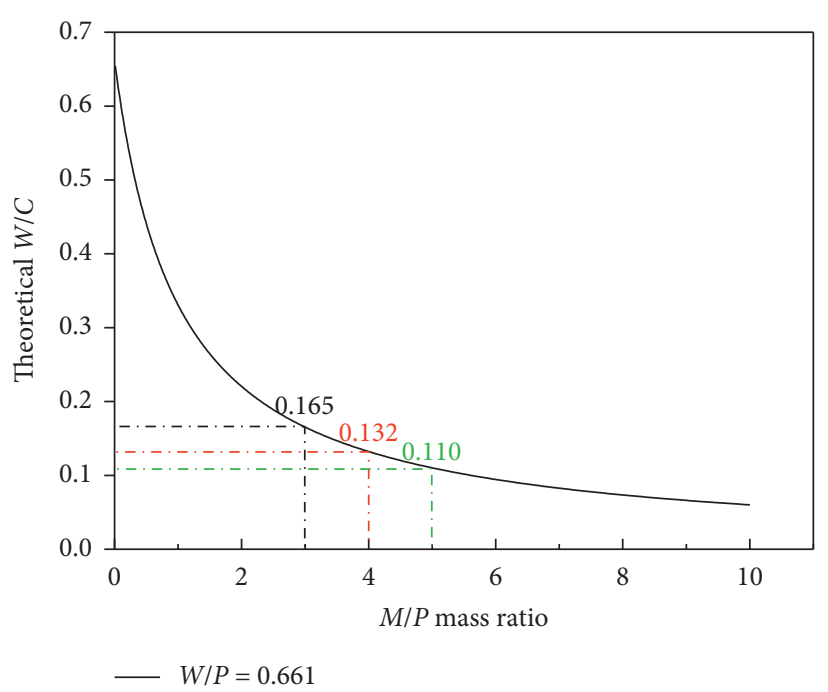

Figure 3: Relationship between the $M / P$ mass ratio and the theoretical $W / C$ ratio.

phosphate cement. Moreover, the volume of MPC shrinks under air-curing conditions at different $M / P$ ratios, which shows that the volume shrinkage of MPC under air-curing conditions may be mainly due to water loss in the system caused by water evaporation.

3.2. Effect of Curing Condition on the Compressive Strength of MPC. The compressive strength of MPC is a critical mechanical index, which can reflect the ability of MPC to resist various loads under different curing conditions. The compressive strength of MPC under various curing conditions is shown in Figure 4. Under the air-curing conditions, the compressive strength of MPC increases rapidly during $21 \mathrm{~d}$ of curing, and then, there will be no obvious increase. However, under the standard and water-curing conditions, the compressive strength of MPC decreases after $21 \mathrm{~d}$ of curing. In Figure 4(a), when the ratio of $M / P$ is $3: 1$ after $28 \mathrm{~d}$ of curing, the compressive strengths of the specimens cured under standard and water conditions were lower than those of the samples cured under air conditions by $21.3 \%$ and $30.7 \%$, respectively. The results show that MPC with high relative humidity will affect the development of the compressive strength. The loss rate of compressive strength increases with humidity, consistent with previous findings [40].

When curing for $28 \mathrm{~d}$, the compressive strengths of MPCs with the $M / P$ ratios of $4: 1$ and $5: 1$ are lower than those of MPC with the $M / P$ ratio of $3: 1$ under water-curing conditions by $35.6 \%$ and $58.4 \%$. The results show that the compressive strength of MPC decreases with the increase in the ratio of $M / P$. The main reason for this phenomenon is that $M / P$ affects the content of hydration products in the MPC. It is generally believed that the hydration product of MPC is $\mathrm{KMgPO}_{4} \cdot 6 \mathrm{H}_{2} \mathrm{O}$, and the excellent adhesion of $\mathrm{KMgPO}_{4} \cdot 6 \mathrm{H}_{2} \mathrm{O}$ makes the remaining $\mathrm{MgO}$ firmly adhere together. At this time, the $\mathrm{MgO}$ has a good framework support. When the amount of $\mathrm{KH} 2 \mathrm{PO} 4$ is constant in the 


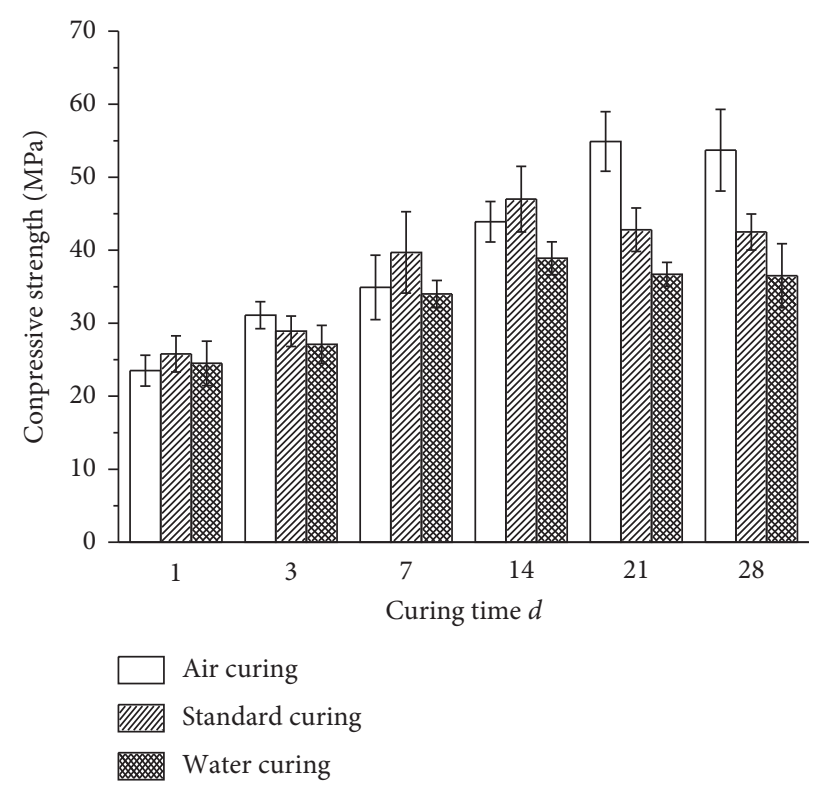

(a)

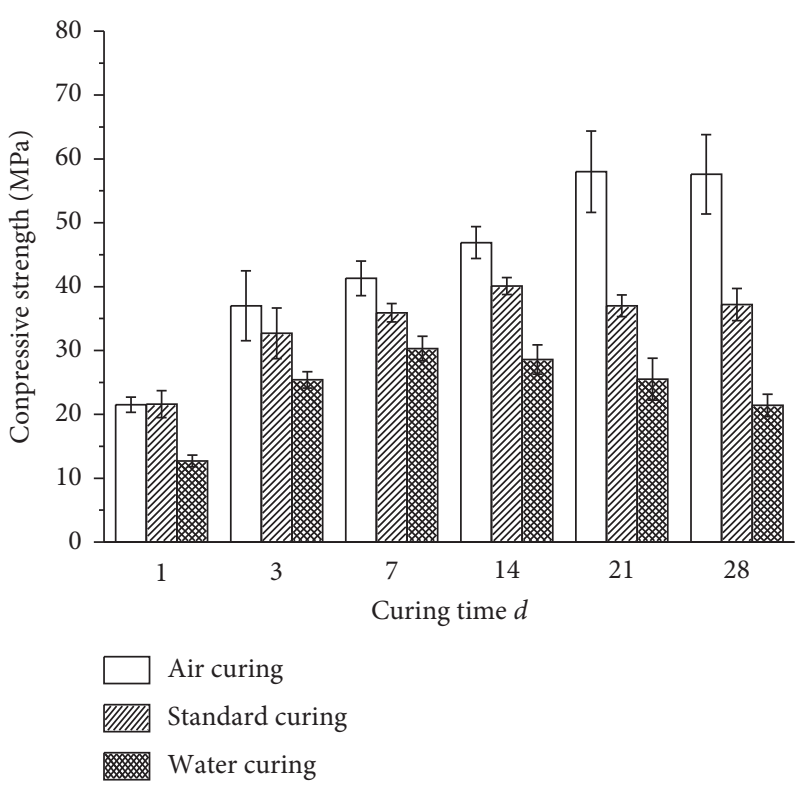

(b)

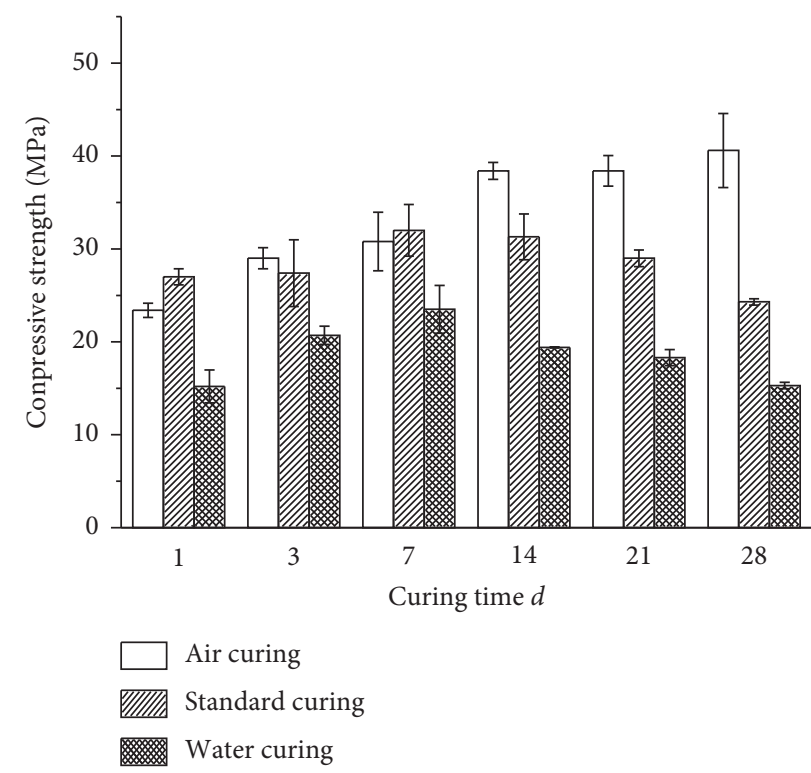

(c)

Figure 4: Compressive strength of MPC under various curing conditions after curing at various ratios. (a) $M / P=3: 1$, (b) $M / P=4: 1$, and (c) $M / P=5: 1$.

sample, there will be an upper limit for the amount of hydrated products of $\mathrm{KMgPO}_{4} \cdot 6 \mathrm{H}_{2} \mathrm{O}$. When the $M / P$ ratio gradually increases, the content of $\mathrm{KH}_{2} \mathrm{PO}_{4}$ will decrease progressively, which makes the $\mathrm{KMgPO}_{4} \cdot 6 \mathrm{H}_{2} \mathrm{O}$ decrease progressively. When the $M / P$ ratio increases, the $\mathrm{MgO}$ content in the system will increase. $\mathrm{KH}_{2} \mathrm{PO}_{4}$ will participate in the hydration reaction to reach the upper limit. The excess $\mathrm{MgO}$ cannot be perfectly combined with the hydration product $\mathrm{KMgPO}_{4} \cdot 6 \mathrm{H}_{2} \mathrm{O}$ with excellent adhesion. Instead, it will damage the further formation of a reticular structure between the hydration products and thus cause a reduction in compressive strength. Therefore, the $M / P$ ratio is one of the critical factors affecting the compressive strength of
MPC, which is the same as in the related studies [41, 42]. In these studies, the researchers speculated that the compressive and tensile bonding strengths of MPC would degrade with the increase in the $M / P$ ratio.

\subsection{Effect of Curing Condition on Formation of the Hydration} Product. Thermogravimetric analysis can observe the substantial mass change of the sample during the heating process. By analyzing the thermogravimetric curve, it can show how many degrees the measured substance changes. According to the loss of weight, it can calculate how many substances are lost. Figure 5 shows the TG curves of MPC with the $M / P$ ratio of $3: 1$ under various curing conditions 


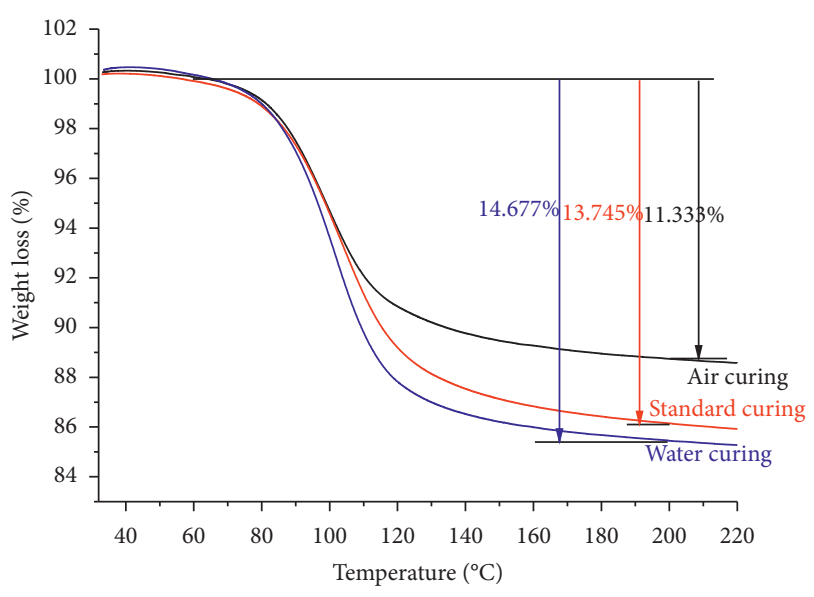

Figure 5: TG curves of MPC with the $M / P$ ratio of $3: 1$ under various curing conditions after curing for $3 \mathrm{~d}$.

after curing for $3 \mathrm{~d}$. It can be seen from the figure that MPC has a weight loss below $200^{\circ} \mathrm{C}$. A previous study shows that the temperature of weight loss by the dehydration of K-struvite is mainly between $60^{\circ} \mathrm{C}$ and $200^{\circ} \mathrm{C}[16,37]$. Therefore, it can be inferred that the mass loss substance of MPC in the range of $60^{\circ} \mathrm{C}$ and $200^{\circ} \mathrm{C}$ is mainly K-struvite. The samples' weight losses are $11.333 \%, 13.745 \%$, and $14.677 \%$ for air, standard, and water-curing conditions, respectively. The hydration products of MPC increase with an increase in humidity. This result is observed because the rise in humidity reduces water evaporation and provides sufficient water for the hydration reaction. There are more hydration products under water-curing conditions than under standard curing conditions, and its volume expansion was greater than that of MPC under standard curing conditions. Therefore, the expansion of MPC is related to hydration products under various curing conditions in the early stage. Volume shrinkage under air curing is due to the drying shrinkage caused by water evaporation in the MPC system, consistent with the theoretical analysis.

Figure 6 shows the TG curves of MPC with the M/P ratio of $3: 1$ under various curing conditions after curing for $28 \mathrm{~d}$. Compared with weight loss for the $3 \mathrm{~d}$ of curing, the hydration products increased by $1.017 \%, 1.066 \%$, and $0.670 \%$ under air, standard, and water-curing conditions, respectively. This shows that the hydration reaction of MPC mainly occurs during the early stage. The development of the strength of MPC is mainly in the early stage, but in the later stage, the growth of the strength is relatively slow. It is implied that the compressive strength of MPC is related to the content of hydration products.

Figures 7 and 8 show the TG curves of MPC under aircuring conditions with different $M / P$ mass ratios after curing for $3 \mathrm{~d}$ and $28 \mathrm{~d}$. Compared with weight loss for the $3 \mathrm{~d}$ of curing, the hydration products increased by $0.896 \%, 1.557 \%$, and $0.123 \%$ for the $28 \mathrm{~d}$ of curing for the $M / P$ ratios of $3: 1,4$ : 1 , and $5: 1$, respectively. Similarly, this shows that the hydration process of MPC with different $M / P$ ratios occurs during the early stage. The shrinkage of sample volume under air-curing conditions is still caused by drying shrinkage.

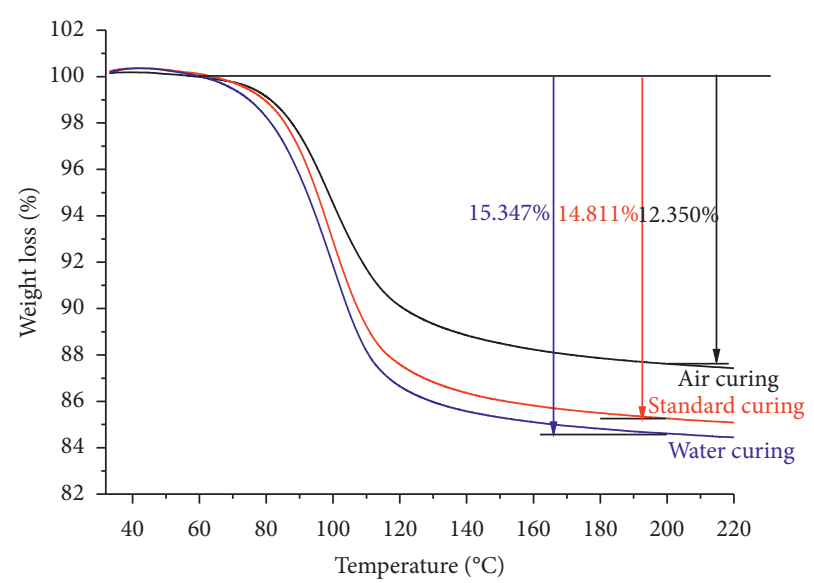

Figure 6: TG curves of MPC with the $M / P$ ratio of $3: 1$ under various curing conditions after curing for $28 \mathrm{~d}$.

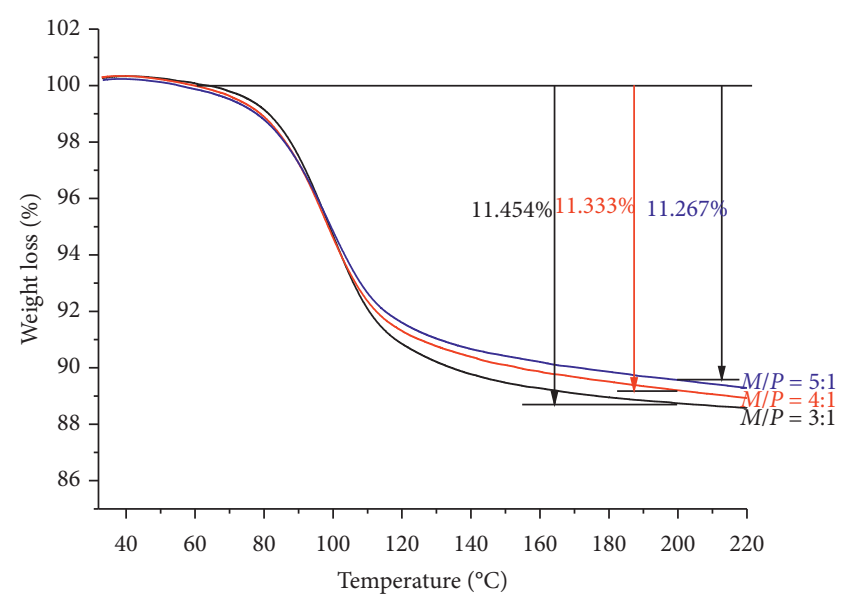

Figure 7: TG curves of MPC with different $M / P$ mass ratios after curing for $3 \mathrm{~d}$ under air-curing conditions.

3.4. Effect of Curing Condition on Phases of MPC. Figure 9 shows the XRD patterns of the solidified forms with the $M / P$ mass ratios of 3 after $28 \mathrm{~d}$ of curing under air, standard, and water-curing conditions. Figure 10 shows the samples' phase analysis with the mass ratios of $M / P$ of $3: 1$, $4: 1$, and $5: 1$ after $28 \mathrm{~d}$ of curing under air-curing conditions. According to the diffraction peaks, the hydration products with various $M / P$ ratios under different curing conditions are $\mathrm{K}$-struvite and $\mathrm{MgO}$. K-struvite is the hydration product of $\mathrm{MgO}$ and $\mathrm{KDP}$. $\mathrm{MgO}$ is the residual deadburned $\mathrm{MgO}$, which is not entirely hydrated. The hydration products' peaks are the same for all samples with various $M$ / $P$ ratios under different curing conditions, and no new characteristic peaks appear. This indicates that the change in curing conditions and $M / P$ ratios do not lead to new hydration products. Through thermal analysis and theoretical analysis, it is concluded that the volume expansion of MPC may be related to the type and quantity of hydration products. However, no new products were found in the $X$ ray diffraction patterns. Therefore, the volume and strength changes of MPC under different curing conditions are 


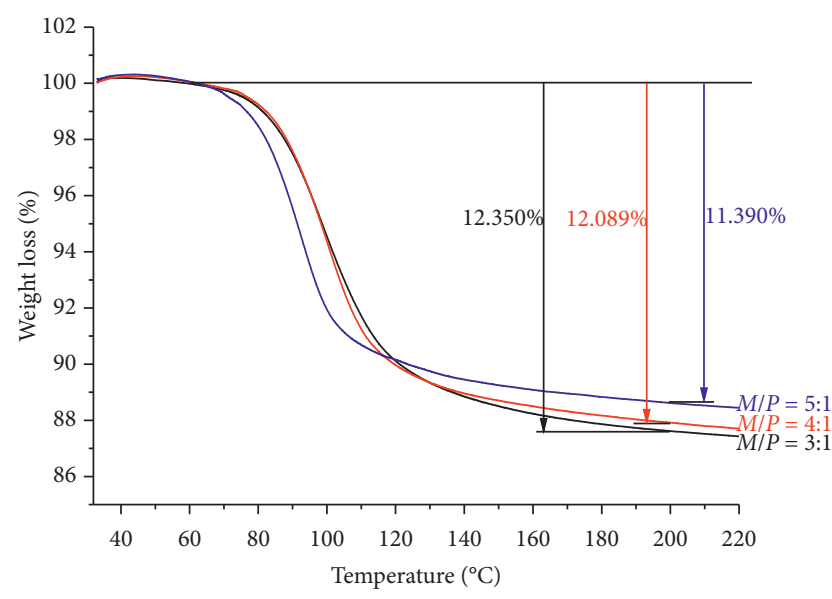

FIgure 8: TG curves of MPC with different $M / P$ mass ratios after curing for $28 \mathrm{~d}$ under air-curing conditions.

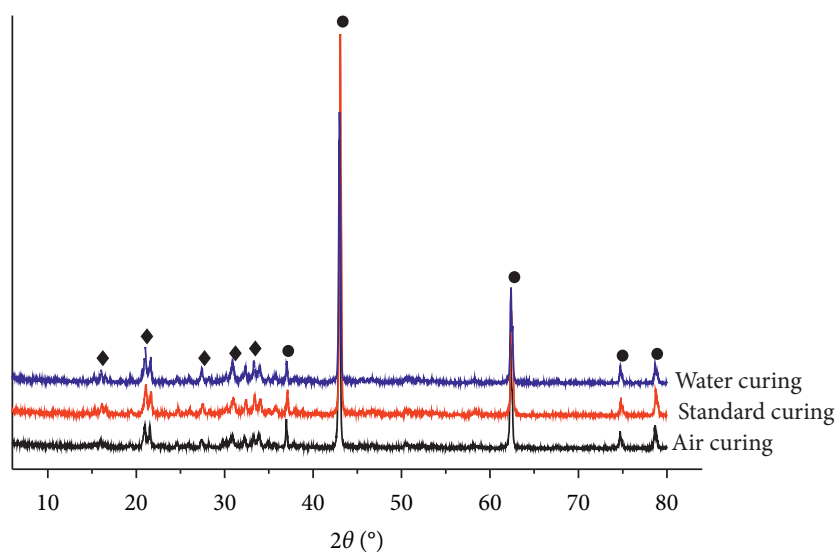

- $\mathrm{MgO}$

- $\mathrm{KMgPO}_{4} \cdot 6 \mathrm{H}_{2} \mathrm{O}$

FIGURE 9: XRD patterns of the samples with the $M / P$ mass ratio of $3: 1$ cured under various curing conditions for $28 \mathrm{~d}$.

independent of the types of hydration products. This implies that the volume change of MPC has a specific relationship with the amount of hydration products.

Figure 11 shows the phase analysis of the leachate of the MPC under water-curing conditions. It is observed that the phase composition includes kovdorskite $\left(\mathrm{Mg}_{2} \mathrm{PO}_{4}(\mathrm{OH})\right.$. $\left.3 \mathrm{H}_{2} \mathrm{O}\right), \mathrm{MgO}$, magnesium phosphate hydrate, and $\mathrm{K}$-struvite. It is indicated that KDP may leach from the system under the water-curing conditions and participate in the reaction with the surface $\mathrm{MgO}$ to generate magnesium phosphate compounds and K-struvite. KDP has a high solubility, which will make the environment around MPC acidic, while K-struvite will dissolve under acidic conditions. It will not only cause more voids in the MPC but also reduces the amount of $\mathrm{K}$-struvite produced. In the early stage of hydration of MPC, $\mathrm{K}$-struvite was formed quickly due to $\mathrm{MgO}$ and $\mathrm{KDP}$, which made the system expand. After $3 \mathrm{~d}$ of curing, due to the leaching of KDP in a humid environment, the amount of $\mathrm{K}$-struvite produced was reduced, and the volume expansion rate of MPC was reduced. However, the leaching of KDP will

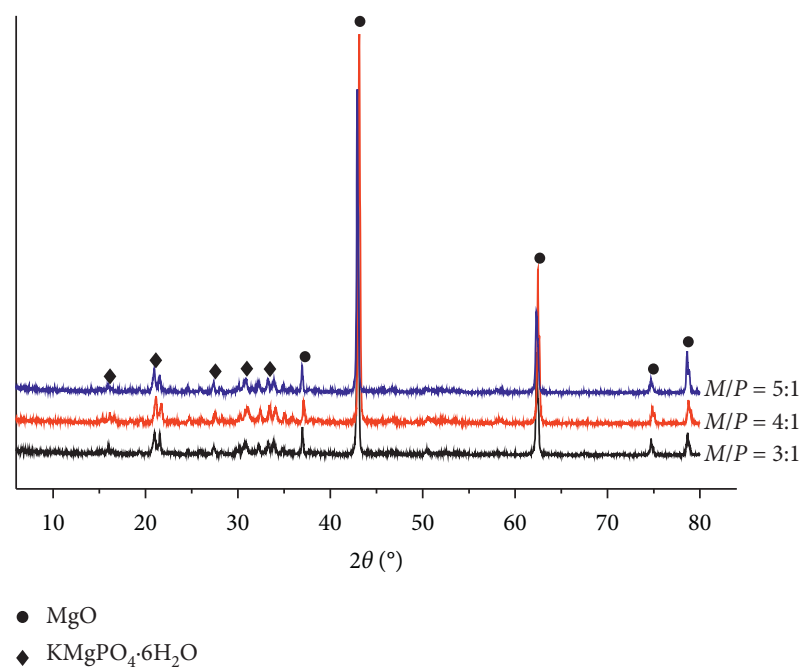

FIGURE 10: XRD patterns of the samples with the $M / P$ mass ratios of $3: 1,4: 1$, and $5: 1$ cured under air-curing conditions for $28 \mathrm{~d}$.

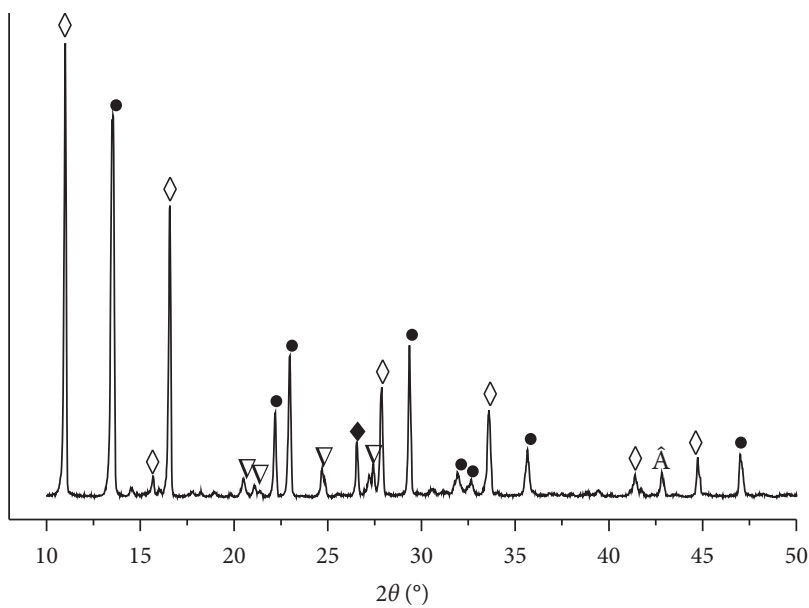

$$
\begin{array}{ll}
\diamond \mathrm{Mg}_{3}\left(\mathrm{PO}_{4}\right)_{2} \cdot 2 \mathrm{H}_{2} \mathrm{O} & \hat{\mathrm{A} \mathrm{MgO}} \\
\text { - } \mathrm{Mg}_{2} \mathrm{PO}_{4}(\mathrm{OH})_{2} \cdot 3 \mathrm{H}_{2} \mathrm{O} & \nabla \mathrm{KMgPO}_{4} \cdot 6 \mathrm{H}_{2} \mathrm{O} \\
\text { - } \mathrm{MgK}_{2}\left(\mathrm{PO}_{3}\right)_{4} &
\end{array}
$$

FIGURE 11: XRD of the magnesium phosphate cement extract.

have certain limitations. When it reaches the limit, it will react with $\mathrm{MgO}$ on the surface of MPC to generate magnesium phosphate compounds and K-struvite. Therefore, there will be a larger expansion trend again under standard and watercuring conditions. As similar to in the previous study, KDP has high solubility and generates porosity caused by the overflow of KDP when samples are under the high humidity condition [7]. Therefore, the increase in porosity reduces the structure's compactness, which leads to a decrease in compressive strength. This is consistent with the reduction of compressive strength caused by the increase in humidity.

3.5. Effect of Curing Condition on the Microstructure of MPC. Figure 12 shows the microstructure of samples under various curing conditions with the $M / P$ ratio of $3: 1$ after $28 \mathrm{~d}$ of curing. Under air-curing conditions, the crystals of 


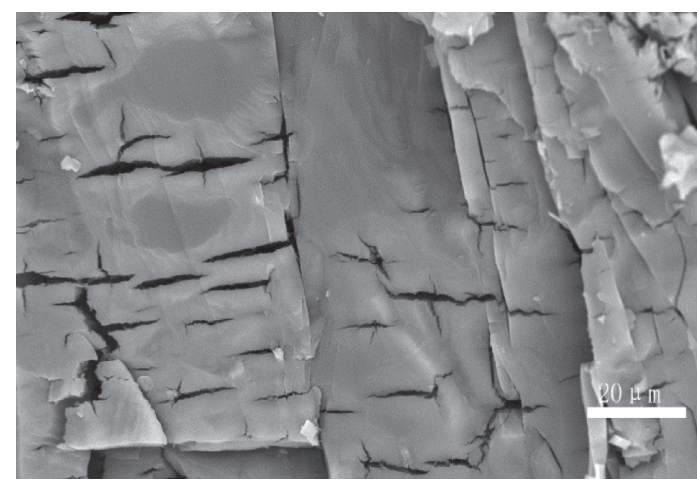

(a)

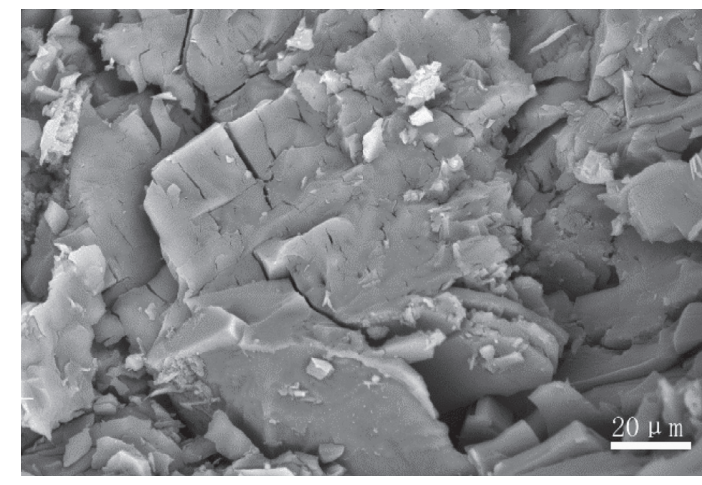

(b)

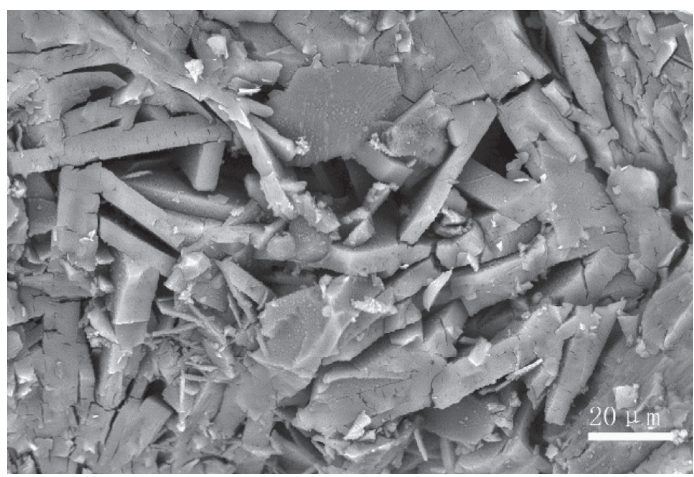

(c)

Figure 12: The samples' microstructure with the $M / P$ ratio of $3: 1$ cured under three curing conditions for 28 d. (a) Air curing. (b) Standard curing. (c) Water curing.

hydration products of MPC primarily appear as plates and prisms, and these crystals are relatively dense. However, under standard and water-curing conditions, although the crystal morphology of the MPC is still an excellent crystalline form, such as a plate or a column, it can be seen that the voids have increased in the system with an increase in humidity. White leachate was found on the surface of MPC, and XRD proves that leachate was a phosphate compound and the hydration products of $\mathrm{K}$-struvite. KDP has high solubility, and it will leach under standard and water-curing conditions. It is speculated that the leaching of KDP causes these voids. Under air-curing conditions, KDP is difficult to leach, which makes MPC denser. This observation confirms that the compressive strength of MPC under air-curing conditions is better than that under standard and watercuring conditions.

Figure 13 shows the microstructure of samples under air-curing conditions with the $M / P$ ratios of $3: 1,4: 1$, and 5 : 1 after $28 \mathrm{~d}$ of curing. The crystals are mainly rodlike and clusterlike when the $M / P$ ratio is high, and the voids of the MPC gradually increased with the increase of the $M / P$ ratio. Since the $\mathrm{MgO}$ in this experiment is dead-burned, $\mathrm{MgO}$ is calcined at $1650^{\circ} \mathrm{C}$, which makes $\mathrm{MgO}$ to not fully participate in the reaction in MPC, and most of the $\mathrm{MgO}$ acts as a framework. The proportion of KDP will gradually decrease with an increase in the $M / P$ ratio, so the amount of hydration products produced will also decrease. When the $M / P$ ratio is 5 , the amounts of hydrated products are relatively small due to less KDP content, making the hydrated products unable to bond well together with dead-burned $\mathrm{MgO}$. A large portion of dead-burned $\mathrm{MgO}$ in the MPC system is simply a physical accumulation, which increases the voids and reduces the compressive strength. Therefore, the porosity of the system increases with the increase in the $M / P$ ratio. The main cause of this phenomenon is the decrease in crystal content, which is consistent with TG.

3.6. Effect of Curing Condition on the Pore Structure of MPC. The cumulative pore volume can reflect the degree of density inside the material. Figure 14 shows the cumulative pore volume of the sample with the ratio of $M / P$ of $3: 1$ for $28 \mathrm{~d}$ of curing under three curing conditions. The cumulative pore volume of samples cured under air conditions is the smallest, while samples cured under water conditions are the largest. This phenomenon may occur because the sample under aircuring conditions becomes dense due to water evaporation, which reduces the porosity and volume shrinkage. This conclusion is consistent with the SEM analysis. This also confirms that the sample has the lowest compressive strength under water-curing conditions.

Figure 15 shows the cumulative pore volume curve of MPC with the $M / P$ ratio of $3: 1,4: 1$, and $5: 1$ after curing for $28 \mathrm{~d}$ under air-curing conditions. The sample has the smallest accumulated porosity with an $M / P$ ratio of 3 . It has the largest cumulative porosity with the $M / P$ ratio of 5 , related to the amount of hydration products. This observation confirms that 


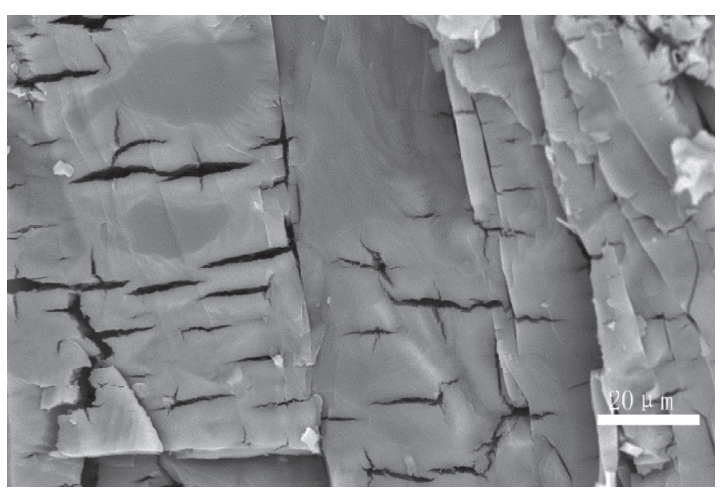

(a)

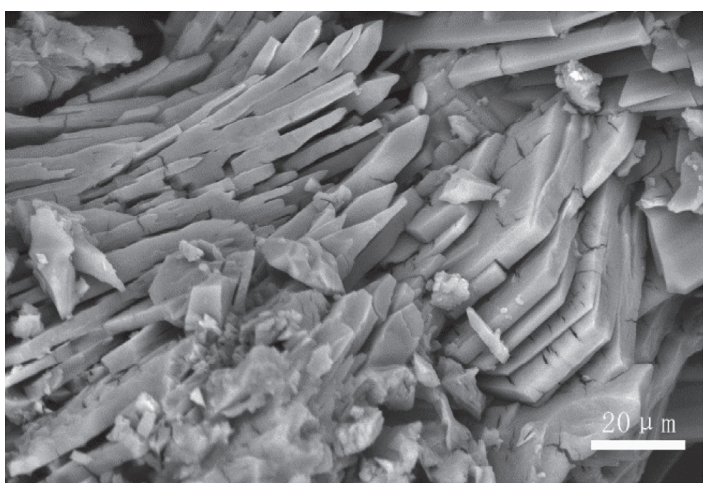

(b)

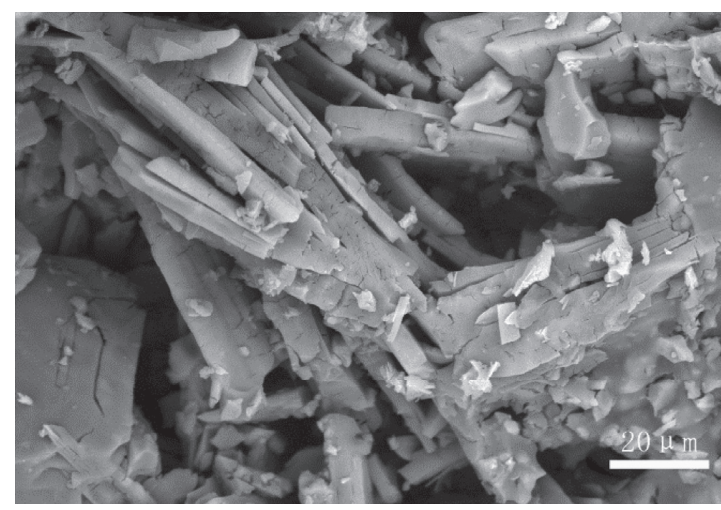

(c)

FIGURE 13: The microstructure of the samples cured under air-curing conditions for $28 \mathrm{~d}$. (a) $M / P=3: 1$, (b) $M / P=4: 1$, and (c) $M / P=5: 1$.

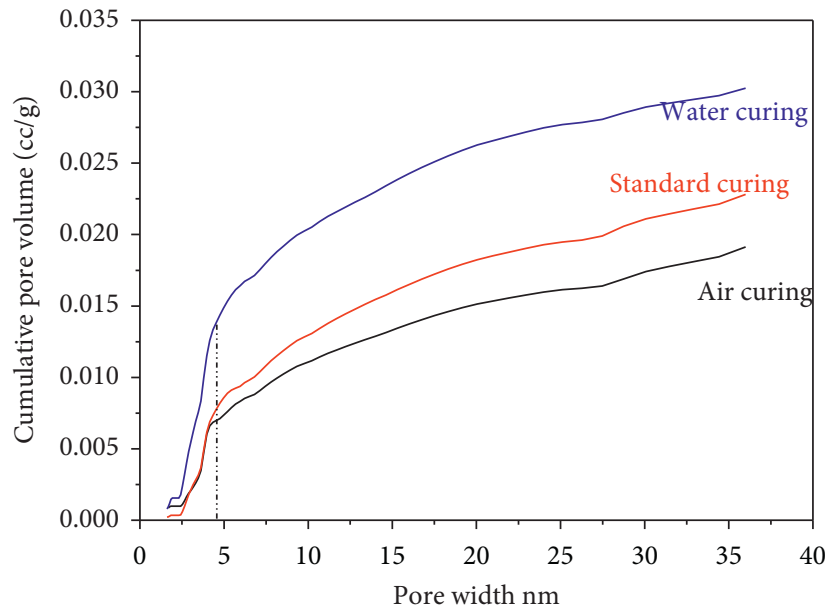

Figure 14: Cumulative pore volume curves of MPC with the $M / P$ ratio of $3: 1$ cured under three curing conditions for $28 \mathrm{~d}$. 


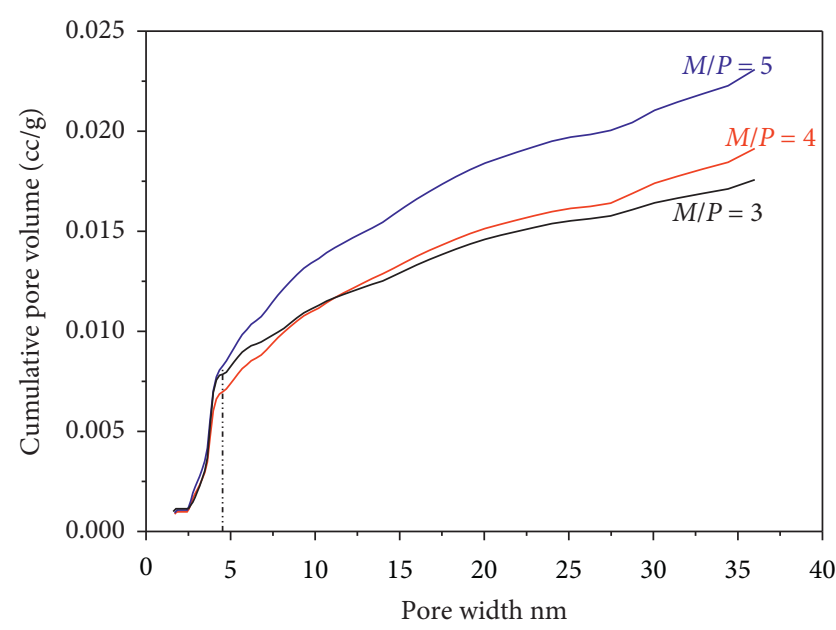

Figure 15: Cumulative pore volume curves of MPC with the $M / P$ ratios of $3: 1,4: 1$, and $5: 1$ cured under air-curing conditions for $28 \mathrm{~d}$.

the volume stability of MPC with the $M / P$ ratio of $3: 1$ is better than that for the $M / P$ ratios of $4: 1$ and $5: 1$.

\section{Conclusions}

The effects of the different curing conditions and the $M / P$ ratio on the volume stability and mechanical properties of magnesium phosphate cement were systematically studied. First, starting from the theoretical water requirement for complete hydration, the effects of curing conditions and $M / P$ on the hydration characteristics of MPC were discussed. Second, its impact on hydration products and the content of the hydration products were studied. Finally, its effects on microstructure and pores were studied. Based on the experimental results obtained in the current study, the following general conclusions can be drawn:

(1) The W/P ratio of MPC when it is completely hydrated is a fixed value of 0.661 . To fully hydrate MPC and thereby improve its mechanical properties, it is proposed to use the $W / P$ ratio as an essential parameter for the performance design of MPC.

(2) The curing conditions affect the mechanical properties and volume stability of MPC. The volume expansion of MPC is related to hydration products, and the volume shrinkage occurs owing to drying shrinkage caused by internal moisture evaporation.

(3) Air curing is the best curing conditions for MPC, and the strength of MPC will shrink under water and standard conditions.

(4) When the water involved in the hydration reaction is insufficient, hydration products' content will increase under standard and water-curing conditions. However, the hydration products and a small amount of unreacted KDP dissolve and hydrolyze in an aqueous solution, which leads to a decrease in structural compactness and compressive strength.

\section{Data Availability}

The datasets used and/or analyzed during the current study are available from the corresponding author upon reasonable request.

\section{Conflicts of Interest}

The authors declare that they have no conflicts of interest regarding the publication of this paper.

\section{Acknowledgments}

The authors thank the Sichuan Science and Technology Program (2020YJ0355) and Southwest University of Science and Technology (nos. 17FKSY0108 and 19FKSY05).

\section{References}

[1] C. Shi, X. Zou, L. Yang, P. Wang, and M. Niu, "Influence of humidity on the mechanical properties of polymer-modified cement-based repair materials," Construction and Building Materials, vol. 261, Article ID 119928, 2020.

[2] T. I. Boykova, V. Y. Solovyova, and D. V. Solovyov, "Effective repair and refurbishment compound for the strengthening of a road concrete pavements," Procedia Engineering, vol. 189, pp. 650-653, 2017.

[3] S.-Y. Guo, X. Zhang, J.-Z. Chen et al., "Mechanical and interface bonding properties of epoxy resin reinforced Portland cement repairing mortar," Construction and Building Materials, vol. 264, Article ID 120715, 2020.

[4] M. M. Al-Zahrani, M. Maslehuddin, S. U. Al-Dulaijan, and M. Ibrahim, "Mechanical properties and durability characteristics of polymer- and cement-based repair materials," Cement and Concrete Composites, vol. 25, no. 4-5, pp. 527537, 2003.

[5] G. Huang, D. Pudasainee, R. Gupta, and W. V. Liu, "Utilization and performance evaluation of molasses as a retarder and plasticizer for calcium sulfoaluminate cement-based mortar," Construction and Building Materials, vol. 243, Article ID 118201, 2020.

[6] L. Zhenyu, W. Hongtao, H. Yang et al., "Rapid solidification of highly loaded high-level liquid wastes with magnesium phosphate cement," Ceramics International, vol. 45, no. 4, pp. 5050-5057, 2019.

[7] M. Le Rouzic, T. Chaussadent, L. Stefan, and M. Saillio, “On the influence of $\mathrm{Mg} / \mathrm{P}$ ratio on the properties and durability of magnesium potassium phosphate cement pastes," Cement and Concrete Research, vol. 96, pp. 27-41, 2017.

[8] A.-j. Wang, X.-j. Fan, J.-m. Li, and D. Chen, "Curing behavior and structure of magnesium phosphate chemically bonded ceramics with different $\mathrm{MgO}$ to KH2PO4Ratios," International Journal of Applied Ceramic Technology, vol. 12, no. 6, pp. 1124-1130, 2015.

[9] Y. Jiang, M. R. Ahmad, and B. Chen, "Properties of magnesium phosphate cement containing steel slag powder," Construction and Building Materials, vol. 195, pp. 140-147, 2019.

[10] M. Le Rouzic, T. Chaussadent, G. Platret, and L. Stefan, "Mechanisms of k-struvite formation in magnesium phosphate cements," Cement and Concrete Research, vol. 91, pp. 117-122, 2017. 
[11] F. Lei, Z. Zhen-ya, W. Xiao-dong, X. Chao, and H. Dongyuan, "Long-term behaviors of phosphate-based rapid repairing material for concrete shafts in coal mines," Journal of Applied Biomaterials \& Functional Materials, vol. 16, no. 3, pp. 171-177, 2018.

[12] M. A. Haque and B. Chen, "Research progresses on magnesium phosphate cement: a review," Construction and Building Materials, vol. 211, pp. 885-898, 2019.

[13] G. Chen, K. Song, X. Huang, and W. Wang, "Removal of toluene and $\mathrm{Pb}(\mathrm{II})$ using a novel adsorbent modified by titanium dioxide and chitosan," Journal of Molecular Liquids, vol. 295, 2019.

[14] A. Whitaker and J. W. Jeffery, "The crystal structure of struvite, $\mathrm{MgNH}_{4} \mathrm{PO}_{4} \cdot 6 \mathrm{H}_{2} \mathrm{O}$," Acta Crystallographica Section $B$ Structural Crystallography and Crystal Chemistry, vol. 26, no. 10, pp. 1429-1440, 1970.

[15] Z. Jiang, C. Qian, and Q. Chen, "Experimental investigation on the volume stability of magnesium phosphate cement with different types of mineral admixtures," Construction and Building Materials, vol. 157, pp. 10-17, 2017.

[16] H. Ma, B. Xu, and Z. Li, "Magnesium potassium phosphate cement paste: degree of reaction, porosity and pore structure," Cement and Concrete Research, vol. 65, pp. 96-104, 2014.

[17] M. Mathew and L. W. Schroede, "Crystal structure of a struvite analogue, $\mathrm{MgKPO}_{4} .6 \mathrm{H}_{2} \mathrm{O}$," Acta Crystallographica Section B Structural Crystallography and Crystal Chemistry, vol. 35, no. 1, pp. 11-13, 1979.

[18] Y. Li, J. Sun, and B. Chen, "Experimental study of magnesia and $M / P$ ratio influencing properties of magnesium phosphate cement," Construction and Building Materials, vol. 65, pp. 177-183, 2014.

[19] R. D. Toledo Filho, K. Ghavami, M. A. Sanjuán, and G. L. England, "Free, restrained and drying shrinkage of cement mortar composites reinforced with vegetable fibres," Cement and Concrete Composites, vol. 27, no. 5, pp. 537-546, 2005.

[20] A. A. Almusallam, "Effect of environmental conditions on the properties of fresh and hardened concrete," Cement \&Concrete Composites, vol. 23, 2001.

[21] J. Liu, D. Deng, and Z. Liu, "Effect of curing methods and wet curing duration on properties of plain and slag-cement concrete," Journal of the Chinese Ceramic Society, vol. 36, no. 7, pp. 901-911, 2008.

[22] A.-j. Wang, Z.-1. Yuan, J. Zhang, L.-t. Liu, J.-m. Li, and Z. Liu, "Effect of raw material ratios on the compressive strength of magnesium potassium phosphate chemically bonded ceramics," Materials Science and Engineering: $C$, vol. 33, no. 8, pp. 5058-5063, 2013.

[23] L. Mo, L. Lv, M. Deng, and J. Qian, "Influence of fly ash and metakaolin on the microstructure and compressive strength of magnesium potassium phosphate cement paste," Cement and Concrete Research, vol. 111, pp. 116-129, 2018.

[24] D. Hou, H. Yan, J. Zhang, P. Wang, and Z. Li, "Experimental and computational investigation of magnesium phosphate cement mortar," Construction and Building Materials, vol. 112, pp. 331-342, 2016.

[25] X. Luo, J.-y. Xu, E.-1. Bai, and W. Li, "Mechanical properties of ceramics-cement based porous material under impact loading," Materials \& Design, vol. 55, pp. 778-784, 2014.

[26] X. Cao, W. Wang, R. Ma, S. Sun, and J. Lin, "Solidification/ stabilization of $\mathrm{Pb} 2+$ and $\mathrm{Zn} 2+$ in the sludge incineration residue-based magnesium potassium phosphate cement: physical and chemical mechanisms and competition between coexisting ions," Environmental Pollution, vol. 253, pp. 171180, 2019.

[27] Y. He, Z. Lai, T. Yan et al., "Effect of $\mathrm{Cd} 2+$ on early hydration process of magnesium phosphate cement and its leaching toxicity properties," Construction and Building Materials, vol. 209, pp. 32-40, 2019.

[28] Y.-S. Wang, J.-G. Dai, L. Wang, D. C. W. Tsang, and C. S. Poon, "Influence of lead on stabilization/solidification by ordinary Portland cement and magnesium phosphate cement," Chemosphere, vol. 190, pp. 90-96, 2018.

[29] S. Muryanto and A. P. Bayuseno, "Influence of $\mathrm{Cu} 2+$ and $\mathrm{Zn} 2+$ as additives on crystallization kinetics and morphology of struvite," Powder Technology, vol. 253, pp. 602-607, 2014.

[30] F. Fu and Q. Wang, "Removal of heavy metal ions from wastewaters: a review," Journal of Environmental Management, vol. 92, no. 3, pp. 407-418, 2011.

[31] C. You, J. Qian, J. Qin, H. Wang, Q. Wang, and Z. Ye, “Effect of early hydration temperature on hydration product and strength development of magnesium phosphate cement (MPC)," Cement and Concrete Research, vol. 78, pp. 179-189, 2015.

[32] Y. Li and B. Chen, "Factors that affect the properties of magnesium phosphate cement," Construction and Building Materials, vol. 47, pp. 977-983, 2013.

[33] A. Viani, K. Sotiriadis, G. Lanzafame, and L. Mancini, “3D microstructure of magnesium potassium phosphate ceramics from X-ray tomography: new insights into the reaction mechanisms," Journal of Materials Science, vol. 54, no. 5, pp. 3748-3760, 2018.

[34] C. K. Chau, F. Qiao, and Z. Li, "Microstructure of magnesium potassium phosphate cement," Construction and Building Materials, vol. 25, no. 6, pp. 2911-2917, 2011.

[35] F. Qiao, C. K. Chau, and Z. Li, "Property evaluation of magnesium phosphate cement mortar as patch repair material," Construction and Building Materials, vol. 24, no. 5, pp. 695-700, 2010.

[36] B. Xu, B. Lothenbach, A. Leemann, and F. Winnefeld, "Reaction mechanism of magnesium potassium phosphate cement with high magnesium-to-phosphate ratio," Cement and Concrete Research, vol. 108, pp. 140-151, 2018.

[37] S. Zhang, H.-S. Shi, S.-W. Huang, and P. Zhang, "Dehydration characteristics of struvite- $K$ pertaining to magnesium potassium phosphate cement system in non-isothermal condition," Journal of Thermal Analysis and Calorimetry, vol. 111, no. 1, pp. 35-40, 2012.

[38] JC/T 313-est Method for Determining Expansive Ratio of Expansive Cement, China Building Materials Press, Beijing, China, 2009.

[39] GB/T 17671-Method of Testing Cements determination of Strength, Standards Press of China, Beijing, China, 1999.

[40] L. I. Dong-xu, L. I. Peng-xiao, and FENGChun-hua, "Research on water resistance of magnesium phosphate cement," Journal of Building Materials, vol. 12, 2009.

[41] H. Ma, B. Xu, J. Liu, H. Pei, and Z. Li, "Effects of water content, magnesia-to-phosphate molar ratio and age on pore structure, strength and permeability of magnesium potassium phosphate cement paste," Materials \& Design, vol. 64, pp. 497-502, 2014.

[42] B. Xu, H. Ma, and Z. Li, "Influence of magnesia-to-phosphate molar ratio on microstructures, mechanical properties and thermal conductivity of magnesium potassium phosphate cement paste with large water-to-solid ratio," Cement and Concrete Research, vol. 68, pp. 1-9, 2015. 